\title{
Development and Validation of a Method for Ionic Dyes Determination in Guava Fibrous Matrix Using Reverse Phase Chromatography
}

\author{
Marina F. dos Reis, ${ }^{a}$ Fabiano A. Silva, ${ }^{b}$ Fernando Madureira, ${ }^{b}$ Eugênia Vargas, ${ }^{b}$ \\ Lucas M. F. Oliveira ${ }^{a}$ and Renata P. Lopes ${ }^{\circledR} *, a$ \\ a Departamento de Química, Universidade Federal de Viçosa, 36570-000 Viçosa-MG, Brazil \\ ${ }^{b}$ Laboratório Federal de Defesa Agropecuária (LFDA/MG), 33600-000 Pedro Leopoldo-MG, Brazil
}

\begin{abstract}
In this work, a method for food dyes determination in fibrous fruit pulps was developed. The analytes Tartrazine, Twilight Yellow FCF, Erythrosine, Orange G and Allura Red were analyzed by reverse phase chromatography with diode array (DAD) detection. The sample preparation consisted of a simple procedure, based on initial $\mathrm{pH}$ adjustment of the sample $(\mathrm{pH}=10.0)$, followed by an extraction with acetonitrile $(5.0 \mathrm{~mL}$ and agitation for $30 \mathrm{~s})$, ultrasonic $(5 \mathrm{~min})$ and centrifugation (4000 rpm, $20^{\circ} \mathrm{C}$, for $20 \mathrm{~min}$ ). The supernatant had its $\mathrm{pH}$ adjusted to 3.0, followed by filtration. The method was validated, with the analytical curves prepared in a matrix, in the range of 50 to $150 \mathrm{mg} \mathrm{kg}^{-1}$ for all the analytes studied (determination coefficients $\left(\mathrm{R}^{2}\right)>0.99$ ). The method veracity was evaluated in terms of recovery, obtaining recoveries of $93-110 \%$. The repeatability was less than $13.7 \%$, while the intermediate precision was less than $19.0 \%$. The limits of detection and quantification were determined, being 15 and $30 \mathrm{mg} \mathrm{kg}^{-1}$, respectively. The combined relative uncertainties were less than $13.8 \%$. Therefore, it can be concluded that a simple method was developed, suitable for monitoring the presence of dyes in fruit pulps in routine analyzes.
\end{abstract}

Keywords: food dyes, fibrous matrices, reverse phase chromatography, HPLC-DAD

\section{Introduction}

Color is one of the main characteristics of food evaluated by the consumer before deciding to buy any product. ${ }^{1}$ Color affects the visual aspect, which is associated with the quality, variety and freshness of food..$^{2}$ Therefore, food dyes are added to foods in order to restore the original appearance lost during the manufacturing process, making them more attractive to consumers. ${ }^{3}$ Food dyes can be classified as natural or artificial. Natural dyes are isolated from plants, fungi or insects, such as chlorophyll and carmine, ${ }^{2,4}$ while artificial dyes are chemically synthesized, ${ }^{5}$ such as Tartrazine, Twilight Yellow FCF, Erythrosine, Orange G and Allura Red (Table S1, Supplementary Information (SI) section). Compared to natural dyes, artificial dyes have advantages such as low cost, high stability and better coloring properties. ${ }^{6}$

The use of one or more synthetic dyes is a frequent way to obtain a more attractive color for the product, ${ }^{7}$ being used in a wide variety of products such as: spices, ${ }^{8}$ wines and soft drinks, ${ }^{9}$ juices and jellies, ${ }^{10}$ sweets and ice cream, ${ }^{4}$

*e-mail: renata.plopes@ufv.br among others. Generally, synthetic dyes have azo functional groups $(\mathrm{N}=\mathrm{N})$ and aromatic rings in their structure, which make them harmful to human health. ${ }^{11}$ These dyes can cause allergies, asthmatic reactions, deoxyribonucleic acid (DNA) damage, hyperactivity, ${ }^{12}$ in addition to being potentially genotoxic, neurotoxic and carcinogenic. ${ }^{6}$ Thus, the use of dyes is controlled worldwide. ${ }^{13}$

In China, the maximum amount allowed for most dyes is less than $100 \mathrm{mg} \mathrm{kg}^{-1} .{ }^{12}$ In the United States, only seven dyes are permitted by the Food and Drug Administration (FDA) as Bright Blue, Indigo Carmine, Fast Green, Allura Red, Erythrosine, Tartrazine and Twilight Yellow. ${ }^{4}$ In Europe, Regulation (EU) No. 1129/2011 ${ }^{14}$ presents the list of additives that can be used and their respective conditions of use, such as the quantity and in which foods they can be applied. In Brazil, the use and the maximum permitted limit of dyes in food is regulated by the National Health Surveillance Agency (ANVISA). ${ }^{13,15}$

In view of the actual regulations in each country, it is necessary that efficient methodologies can be developed to monitor the amount of food coloring in foods..$^{10}$ For this, the high-performance liquid chromatography technique coupled to sequential mass spectrometer (HPLC-MS/MS) 
is widely used in the determination and quantification of food dyes in different matrices. Tsai et al. ${ }^{16}$ developed a method for determining 20 synthetic dyes in powdered peppers and preserved fruits using HPLC/MS-MS, in which limits of quantification between 0.001 and $1.00 \mathrm{mg} \mathrm{kg}^{-1}$ and recoveries greater than $90 \%$ were obtained for all analytes. Chen et al. ${ }^{9}$ developed a method for determining dyes in carbonated drinks and wines by HPLC-MS/MS, obtaining limits of quantification between 1.51 and $5.00 \mu \mathrm{g} \mathrm{L}^{-1}$ and recoveries between 84 and $116.2 \%$, for all analytes.

Although the HPLC-MS/MS is efficient, it is an expensive technique, with expensive inputs and maintenance, in addition to requiring highly trained analysts. High performance liquid chromatography coupled to the diode array detector (HPLC-DAD), on the other hand, is a cheaper technique compared to HPLC-MS/MS, and it provides adequate robustness, sensitivity and selectivity. ${ }^{17}$

Another important point to consider is the columns used to separate these analytes. Ion exchange columns are excellent for the analysis and determination of food dyes by HPLC, ${ }^{18}$ important in the analysis of ionic and highly polar compounds. ${ }^{19}$ However, they are very specific columns and are not generally accessible to laboratories. Reverse phase columns, on the other hand, are quite versatile, allowing the separation of numerous compounds, being a common input in chromatographic laboratories. However, the use of reverse phase is challenging for the analysis of food dyes. Due to their highly polar nature, they are commonly eluted in the dead time..$^{20}$

In order to make the analysis of food dyes via reverse phase chromatography feasible, several studies report the need to recondition the column before making new injections. Prado and Godoy, ${ }^{21}$ for example, developed a method by HPLC-DAD for the analysis of dyes in gelatin powder samples, in which they report the preconditioning of the column by the mobile phase consisting of $70 \%$ solution ammonium acetate $\left(0.08 \mathrm{~mol} \mathrm{~L}^{-1}\right): 30 \%$ methanol. According to the authors, the conditioning improved the resolution between the peaks because the mobile phase supplied and/or reduced the solubility of the dye in the mobile phase, favoring the interaction of these compounds with the stationary phase. Iammarino $\mathrm{et} \mathrm{al.} .^{22}$ also describe the need to recondition the column before making new injections in the analysis of 12 food dyes in meat products using HPLC-DAD. These authors used a mobile phase consisting of $0.02 \mathrm{~mol} \mathrm{~L}^{-1}$ acetate buffer ( $\mathrm{pH} 7.0$ ).

Fruit pulps are matrices composed mostly of dietary fibers. ${ }^{23}$ Depending on the physical-chemical characteristics of the analytes and the $\mathrm{pH}$ value of the matrix, the interaction between the dyes and the matrix can be favored, making the extraction process a great challenge. Therefore, work involving analysis of ionic dyes in fibrous matrices is scarce. In view of the above, the objective of this work was to develop and validate a simple and fast method for determination of five food dyes (Twilight Yellow FCF, Erythrosine, Orange G, Tartrazine and Allura Red) in fibrous fruit pulp by reverse phase chromatography.

\section{Experimental}

\section{Reagents and standards}

The standards Tartrazine (purity $\geq 85 \%$; CAS: 1934-21-0), Twilight Yellow FCF (purity $\geq 90 \%$; CAS: 2783-94-0) and Orange G (purity $\geq 80 \%$; CAS: 1936-15-8) were obtained from Sigma-Aldrich (St. Louis, MO, USA). The Erythrosine standard (purity $\geq 95 \%$; CAS: 15905-32-5) was obtained from Riedel-De Haën (Seelze, HA, Germany) and the Allura Red standard (purity $\geq 80 \%$; CAS: 25956-17- 6) was obtained from TCI América (Portland, OR, USA).

The HPLC-grade acetonitrile was obtained from Merck (Darmstadt, HE, Germany) and J. T. Baker Chemical Co. (Phillipsburg, NJ, USA). Hydrochloric acid was obtained from Isofar (Duque de Caxias, RJ, Brazil); formic acid with Exodus Científica (Sumaré, SP, Brazil) and sodium hydroxide with Merck (Darmstadt, HE, Germany) and the surfactant Tween 20 (CAS: 9005-64-5) with CRQ Produtos Químicos (Diadema, SP, Brazil). All solutions were made with water type 1 , obtained by the Milli-Q system (Millipore, Bedford, MA, USA).

Individual stock solutions of each dye (5000 $\left.\mathrm{mg} \mathrm{L}^{-1}\right)$ were prepared in type 1 water. The working solution containing all dyes $\left(500 \mathrm{mg} \mathrm{L}^{-1}\right)$ was prepared daily from the dilution of the stock solutions. All solutions were stored under refrigeration at $10{ }^{\circ} \mathrm{C}$.

Instrumentation

The chromatography equipment was a Nexera X2 model with an LC-30AD pump coupled to an SPD-M20 diode array detector (Kyoto, Japan, Shimadzu). The separation was performed on a LUNA C18 column $(150 \times 3.0 \mathrm{~mm}$, $3.0 \mu \mathrm{m})$ (California, USA, Phenomenex), oven temperature: $30^{\circ} \mathrm{C}$; injection volume: $10 \mu \mathrm{L}$, flow rate: $0.375 \mathrm{~mL} \mathrm{~min}^{-1}$.

The mobile phase consisted of a solution of $0.15 \%$ formic acid and $2.03 \times 10^{-12} \mathrm{~g} \mathrm{~mL}^{-1}$ of tween 20 in water:acetonitrile $(80: 20, \mathrm{v} / \mathrm{v})($ solvent $\mathrm{A})$ and $0.10 \%$ formic acid in acetonitrile (solvent B). To achieve a successful resolution of all dyes, several gradient elution programs have been tested. The optimized final gradient consists of the following steps: 0-4 min: 100\% solvent A; 4-6.5 min: $100-93 \%$ solvent $\mathrm{A} ; 6.5-10$ min: $93-90 \%$ solvent $\mathrm{A}$; 
10-12 min: $90 \%$ solvent A; $12-13$ min: $90-83 \%$ solvent A; 13-15 min: 83-10\% solvent A; $15-21$ min: $10-0 \%$ solvent $A$; 21-25 min: $0 \%$ solvent $\mathrm{A} ; 25-26$ min: $0-20 \%$ solvent $\mathrm{A}$; 26-27 min: $20-100 \%$ solvent A; $27-30 \mathrm{~min}: 100 \%$ solvent $\mathrm{A}$. When a different gradient was used, it will be specified. Between analyzes it was necessary to condition the column using the following gradient: 0-25 min: 100\% solvent A; 25-30 min: $95 \%$ solvent A. This condition was obtained empirically, as the dyes were retained within the column. Among the numerous conditions evaluated, this was the one that presented the best result.

A photodiode array detector was used. The maximum absorption wavelengths of the dyes were determined, being: $430 \mathrm{~nm}$ for Tartrazine, $485 \mathrm{~nm}$ for Twilight Yellow and Orange G, $510 \mathrm{~nm}$ for Allura Red and $540 \mathrm{~nm}$ for Erythrosine.

\section{Chromatographic conditions optimization}

Three chromatographic conditions were analyzed in order to obtain the best analysis condition. The first condition consisted of a gradient elution using a solution of $0.01 \mathrm{~mol} \mathrm{~L}^{-1}$ ammonium acetate and acetonitrile (90:10, v/v) (solvent $\mathrm{A}$ ) and $0.1 \%$ ammonium acetate in acetonitrile (solvent B). In the second condition, a previous conditioning of the column was carried out by passing a mobile phase of $0.1 \mathrm{~mol} \mathrm{\textrm {L } ^ { - 1 }}$ ammonium acetate in water:methanol $(70: 30, \mathrm{v} / \mathrm{v})$ and isocratic elution using the mobile phase water:methanol (70:30, v/v). Finally, the third condition consisted of gradient elution using a mobile phase containing three different concentrations of formic acid $(0.09 ; 0.10$ and $0.15 \%)$ in water and acetonitrile $(80: 20, \mathrm{v} / \mathrm{v})$ (solvent A) and $0.10 \%$ formic acid in acetonitrile (solvent B).

\section{Sample preparation}

For the extraction of dyes, $5.0 \mathrm{~g}$ of sample (guava pulp) were weighed, which had the $\mathrm{pH}$ adjusted to 10.0 with $\mathrm{NaOH}\left(1.0 \mathrm{~mol} \mathrm{~L}^{-1}\right)$. Then, $5.0 \mathrm{~mL}$ of extracting solvent (acetonitrile) was added with stirring for $30 \mathrm{~s}$. After sonication for $5 \mathrm{~min}$, the samples were centrifuged at $4000 \mathrm{rpm}$, at $20^{\circ} \mathrm{C}$, for $20 \mathrm{~min}$. The samples supernatant was carefully separated, which had its $\mathrm{pH}$ again adjusted to 3.0 with $\mathrm{HCl}(1.0 \mathrm{~mol} \mathrm{~L}-1)$. The extracts were filtered using $0.45 \mu \mathrm{m}$ polytetrafluoroethylene (PTFE) membrane filters. $600 \mu \mathrm{L}$ of the extract were transferred to vials, with subsequent sample dilution containing $2.03 \times 10^{-12} \mathrm{~g} \mathrm{~mL}^{-1}$ of tween $20(3: 2, \mathrm{v} / \mathrm{v})$. The optimized sample preparation is outlined in Figure 1.

\section{Method validation}

The validation of the method was carried out in accordance with the Analytical Quality Assurance Manual for Residues and Contaminants in Food, of the Ministry of Agriculture, Livestock and Supply (MAPA, Brazil, 2011) ${ }^{24}$ and with SANTE/11813/2017 (European Commission, 2017). ${ }^{25}$ In addition, the Guide for Expression of Measurement Uncertainty ${ }^{26}$ was used to calculate the uncertainty of analytical measurement.

The figures of merit analyzed were: linearity, veracity, repeatability, intermediate precision, limit of detection (LOD), limit of quantification (LOQ) and analytical measurement uncertainty. All parameters were calculated considering $100 \mathrm{mg} \mathrm{kg}^{-1}$ as the maximum residue limit (MRL) for all food colors.

The analytical curves were constructed in matrix extract at a concentration of $0.5 ; 0.75 ; 1.0 ; 1.25$ and $1.5 \times$ MRL. Each concentration was prepared in triplicate independently. The quality of the curve was assessed by the coefficient of determination and by linearity test, according to equation 1 .

$t_{r w}=\left|r_{w}\right| \sqrt{\frac{N_{x}-2}{1-r_{w}^{2}}}$

where: $r_{w}$ is the linear correlation coefficient, $N_{x}$ is the degrees number of freedom and $t_{r w}$ is the desired value, that is, calculated. If the calculated value is greater than critical

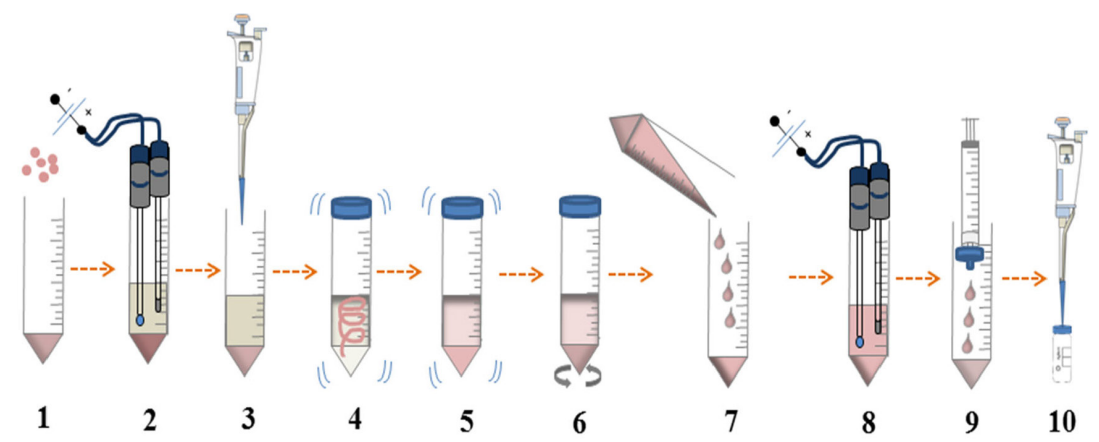

Figure 1. Scheme of sample preparation developed, being: 1: $5.0 \mathrm{~g}$ of sample; 2: adjustment to $\mathrm{pH}$ 10.0; 3: addition of extractor solvent; 4: agitation; 5: sonication; 6: centrifugation; 7: separation of the supernatant; 8: adjustment to $\mathrm{pH}$ 3.0; 9: filtration; 10: dilution of the sample. 
(tabulated, for a $95 \%$ confidence level) and $\left(\mathrm{N}_{\mathrm{x}}-2\right)$ degrees of freedom, the range is considered to be linear.

Veracity, repeatability (intraday precision) and intermediate precision (interday precision) were evaluated by recovery assays, in which white samples were fortified at three different concentration levels: $0.5 ; 1.0$ and 1.5 times the MRL, with replicates performed at each level $(n=6)$. Repeatability was estimated by analyzing the relative standard deviations (RSD) between the results of the same concentration level on the same day. The intermediate precision was estimated by analyzing the RSD between the results of the same concentration level on three different days. The first point of the curve was assumed to be LOQ and LOD being half the value of LOQ. Therefore, LOQ and LOD were 50 and $25 \mathrm{mg} \mathrm{kg}^{-1}$, respectively.

For the calculation of analytical measurement uncertainty, the top-down methodology was used, seeking to make a combination of the main sources of uncertainty in the measurement procedure. The equation 2 was used to estimate uncertainty, using a $95 \%$ confidence level and a coverage factor $(\mathrm{k})$ of 1.96 .

$\mathrm{c}_{\text {analyte }}\left(\mathrm{mg} \mathrm{kg}^{-1}\right)=\frac{(\mathrm{CASP}-\mathrm{a})}{\mathrm{b}}+\mathrm{C}_{\mathrm{PII}}$

where CASP is the chromatographic area of the sample peak, $a$ is the intercept of the analytical curve, $b$ is the slope of the analytical curve; $\mathrm{CP}_{\mathrm{II}}$ is the uncertainty arising from the intermediate precision of the method.

The acceptability criterion for uncertainty is given by equation $3 .{ }^{24}$ Considering the relative standard deviations of intermediate precision $\left(\mathrm{RSD}_{\mathrm{IP}}\right)$ adopted as $20 \%$, the value of the combined relative uncertainty should not exceed $27 \%$.

$\frac{\mathrm{u}_{\mathrm{c}}\left(\mathrm{c}_{\text {analyte }}\right)}{\mathrm{c}_{\text {analyte }}} \leq\left(1+\frac{1}{3}\right) \times \mathrm{RSD}_{\mathrm{IP}}$

wherein: $u_{c}$ is the combined uncertainty, $c_{\text {analyte }}$ is the concentration of the analyte in the sample and $\mathrm{RSD}_{\mathrm{IP}}$ is the relative standard deviations of intermediate precision established.

\section{Analysis of authentic samples}

The validated method was applied to the analysis of eight authentic guava pulp samples $\left(A_{1}\right.$ to $\left.A_{8}\right)$ acquired in supermarkets in Belo Horizonte, Viçosa and Ubá (Minas Gerais, Brazil). After visual inspection, the samples were removed from the original packaging, stored in inert plastic bottles and stored in a cold chamber at $-10{ }^{\circ} \mathrm{C}$ until the time of analysis.

\section{Results and Discussion}

First, the chromatographic method was optimized for the determination of Twilight Yellow FCF, Erythrosine, Orange G, Tartrazine and Allura Red dyes using a mobile phase with ammonium acetate, well known as a modifier in the separation of azo dyes. ${ }^{13}$ It was used as an ion pairing agent in C18 columns. ${ }^{20}$ The analytes were injected individually, so that it was possible to determine the retention time of each one. The results are shown in Figure S1 (SI section). As can be seen, the retention times were different for all analytes, that is, $1.8 ; 5.9 ; 8.2 ; 8.7$ and 9.7 min for Tartrazine, Twilight Yellow, Orange G, Allura Red and Erythrosine, respectively. However, when making an injection of the analyte pool, there was no separation of the compounds, with a co-elution being observed in approximately $2 \mathrm{~min}$, as can be seen in Figure S2 (SI section). Due the ionic character of the analytes, this result suggests that there is a strong interaction between the compounds, due to the distribution of charges in the molecule, which leads to co-elution.

Therefore, it was proposed to condition the column before the injections using a mobile phase containing ammonium acetate. According to de Andrade et al. ${ }^{5}$ the addition of an ionic substance, such as ammonium acetate, significantly increases the retention time of the compounds because ionic pairs are created in the mobile phase and the retention is controlled by the interaction of the compounds with the stationary phase. However, the conditioning of the column was not efficient for the separation of the analytes, with a new co-elution in approximately $2 \mathrm{~min}$, as can be seen in Figure S3 (SI section).

Given the results obtained previously, a change in chromatographic conditions was proposed. Molognoni et al., ${ }^{27}$ in his work of food preservatives determination in meat and fish, claim that the use of formic acid as an additive in the mobile phase improved the separation of all analytes, eliminating the use of buffers. Thus, the composition of the mobile phase was altered and the use of formic acid as a column modifier was evaluated. The result is shown in Figure S4 (SI section). As can be seen, the modification presented a better result than those obtained previously, however, it was not yet possible to identify the peaks for each analyte. In addition, when reinjecting the pool in the same condition, a new co-elution of the analytes occurred in 2 min of running, indicating that there was no reproducibility between the analyzes.

Finally, the use of a surfactant in the pool solution of the analyte standards $\left(8.15 \mathrm{mmol} \mathrm{L}^{-1}\right)$ was proposed, maintaining the composition of the mobile phase used previously, in order to ensure reproducibility between 
the analyzes. Vidotti et al. ${ }^{10}$ used a nonionic surfactant in the mobile phase to allow the separation of food dyes. According to the authors, the use of surfactant alters the mechanism of interaction between the dyes and the C18 column, as this compound is absorbed by the stationary phase, increasing its polarity. Thus, tween 20 (Figure S5, SI section) was used as a stationary phase modifier. The Figure S6 (SI section) shows the result obtained. As can be seen, the presence of the surfactant in solution allowed the separation of the analytes, in addition to ensuring repeatability between consecutive injections.

It is proposed that the use of the surfactant, as described by Vidotti et al., ${ }^{10}$ creates a layer in the $\mathrm{C} 18$ stationary phase, modifying its nonpolar characteristics, allowing the analytes to interact more efficiently with the column, allowing its separation. Therefore, the constant use of surfactant in solution was no longer necessary. Empirically, the surfactant concentration in the samples was reduced, until it did not contain this compound in solution. It is important to note that high concentrations of surfactant displace the baseline in a chromatographic run.

However, it was still necessary to improve the chromatographic resolution. Thus, it was decided to evaluate different concentrations of formic acid in the aqueous mobile phase in order to achieve the desired objective. It was observed that the highest concentration of formic acid allows a better resolution of the peaks and, therefore, was chosen for the further analysis. The chromatogram with the best mobile phase condition is shown in Figure 2. It is important to note that a conditioning time of $30 \mathrm{~min}$ between injections is necessary, so that the analyzes are reproductive. A similar procedure was described by Prado and Godoy ${ }^{21}$ in the determination of five dyes in gelatin powder samples.

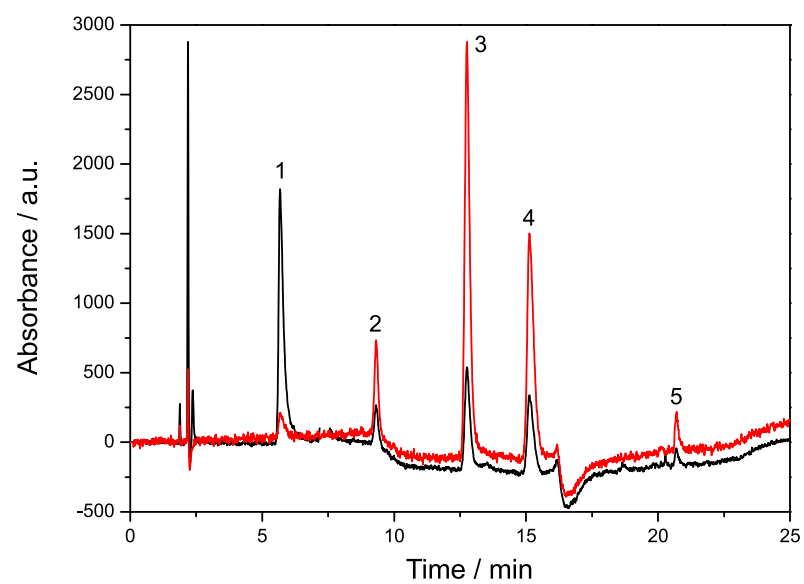

Figure 2. Overlapping chromatograms obtained from the injection of the analyte pool (15 mg L-1 for Tartrazine, Allura Red and Orange G; $50 \mathrm{mg} \mathrm{L}^{-1}$ for Twilight Yellow; $100 \mathrm{mg} \mathrm{L}^{-1}$ for Erythrosine) at 400 and $500 \mathrm{~nm}$. Mobile phase: (A) $0.15 \%$ formic acid in water and acetonitrile (80:20, v/v) and (B) $0.1 \%$ formic acid in acetonitrile. The analytes: 1: Tartrazine; 2: Twilight Yellow; 3: Orange G; 4: Allura Red; 5: Erythrosine.

\section{Sample preparation}

Sample preparation is a fundamental step in the analysis process, as it aims to minimize the possible interferences of the matrix, before it is inserted in the analysis instruments. ${ }^{28}$ Foods, in general, are quite complex matrices and, therefore, it is necessary to pre-treat these samples, so that they are suitable for analysis. In this way, the aim of this work was to develop a simple, fast and efficient method of extracting food dyes from guava pulp. First, a sample preparation process without the use of solvents was tried, consisting only of centrifugation before injection in HPLC-DAD. However, this procedure did not show good results, with coefficients of variation above $30 \%$, indicating a lack of reproducibility between the replicates. Thus, a sample preparation using solvent in order to achieve the desired reproducibility was tried.

In this sense, the sample was prepared using acetonitrile as the extracting solvent in the presence of $0.1 \mathrm{~mol} \mathrm{~L}^{-1} \mathrm{NaCl}$. The presence of salt was expected to favor the extraction of analytes. ${ }^{29}$ However, the desired result was not observed, since the analytes Tartrazine and Twilight Yellow FCF were not extracted, while the others obtained high values of coefficient of variation. Therefore, it was decided to study the effect of different solvents and also different initial $\mathrm{pH}$ values of the sample in the extraction procedure. For the study of the best extracting solvent, methanol, acetone and acetonitrile were used. The three solvents used showed similar behavior in the extraction of the analytes (Figures S7 and S8, SI section). Therefore, it was decided to use acetonitrile, as this way, the sample has a condition similar to the conditions used in the mobile phase.

For the evaluation of initial $\mathrm{pH}$ effect of the sample in the extraction procedure, a study was made considering the natural $\mathrm{pH}$ of the matrix $(\mathrm{pH}=4.5)$ and $\mathrm{pH}$ values in acid and basic character $(3.0 ; 6.0 ; 8.0$ and 10.0). It was observed that at $\mathrm{pH} 10.0$ the extraction of the analytes occurred more efficiently. This is due to the fact that the guava pulp is made up, for the most part, of dietary fibers (ca. 49\%). ${ }^{23}$ Cellulosic fiber-based materials have a zero charge point (PCZ) of approximately 7.0. ${ }^{30}$ Thus, at $\mathrm{pH}$ values below the PCZ, the charge on the surface of the cellulosic material is positive and strongly attracts anionic dyes, as described by Salleh et al. ${ }^{31}$ On the other hand, at $\mathrm{pH}$ values above the PCZ, extraction is favored, as the material will have a negative surface charge, repelling anionic dyes. The interaction model between anionic dyes at $\mathrm{pH}$ values below and above the PCZ is shown in Figure 3.

After extraction, however, the $\mathrm{pH}$ of the extract had to be adjusted again to 3.0, as this procedure allowed for better chromatographic resolution and better peak shape. The use 


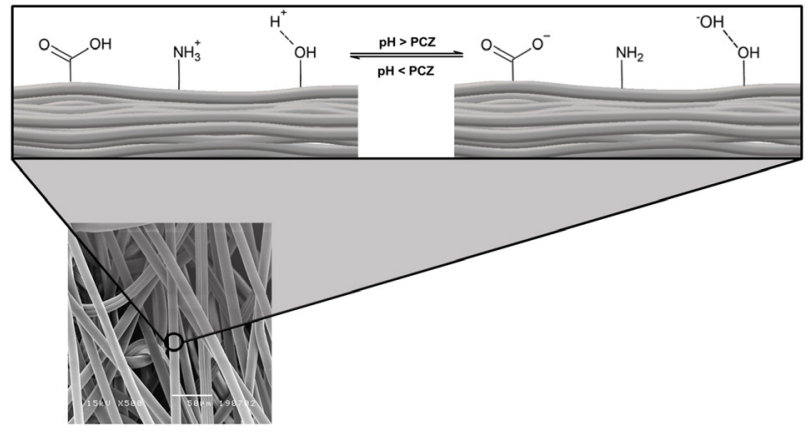

Figure 3. Scheme of surface loads of cellulosic fibers with the $\mathrm{pH}$ variation of the medium (reproduced from reference 32 with copyright permission 2016 from Elsevier).

of ultrasound in sample preparation has also been studied, with a very positive effect on the extraction procedure. As described by Tiwari, ${ }^{33}$ when ultrasound propagates in the sample, it induces a series of compressions and rarefactions of the medium. These alternating pressure changes cause the formation and collapse of microbubbles, a phenomenon known as acoustic cavitation. The temperature and pressure changes that occur to a minuscule level with these implosions cause shear disruption, thinning of cell membranes and cell disruption, resulting in greater solvent penetration into the sample and amplification of the mass transfer of the analytes to the solvent. Therefore, the use of sonication improves the extraction yield and the quality of the extract.

\section{Method validation}

The analytical curves were constructed in a matrix and the results obtained are shown in Table 1. According to the standards used, the results found are satisfactory, with determination coefficients $\left(\mathrm{R}^{2}\right)$ values greater than 0.99871 . In addition, it is possible to conclude that the working range chosen is linear by the linearity test, since the $t_{\text {calculated }}$ value is greater than the $t_{\text {critical }}$ value for all analytes.

The values for LOD and LOQ were determined, being 15 and $30 \mathrm{mg} \mathrm{kg}^{-1}$, respectively. The values of LOD and LOQ are considered satisfactory, since they are well below the MRL values considered for the analytes under study, indicating that the method is capable of detecting and quantify these substances even in small concentrations.

The veracity of the method, repeatability and intermediate precision were evaluated by means of recovery tests and the results are shown in Table 2. It can be seen that the values found were satisfactory, with recoveries between $93-110 \%$ for all analytes, and relative standard deviations of repeatability and intermediate precision below 14 and 20\%, respectively, except for Erythrosine at the third level. This result indicates that this analyte cannot be quantified in this concentration range. Similar results were found by Sha et al.,${ }^{34}$ which uses ionic liquidmediated microextraction to determine Tartrazine, Twilight Yellow, Amaranth, Ponceau 4R, and Bright Blue dyes in soft drinks, powdered soft drinks and gelatine samples using HPLC-DAD in reverse phase. According to the authors, recoveries were 93.2-98.9\% and RSD between 1.6-3.2\%. However, the advantage of the method proposed in this work is simplicity in the extraction process.

The results of the measurement uncertainty are shown in Table 3, whose combined relative uncertainty values were less than $27 \%$. Thus, it is concluded that the results found are satisfactory for all analytes, as established by the

Table 1. Equations of analytical curves, determination coefficients $\left(\mathrm{R}^{2}\right)$ and parameters of the linearity test obtained for food dyes

\begin{tabular}{lcccc}
\hline Analyte & $\begin{array}{c}\text { Analytical curve working } \\
\text { range } /\left(\mathrm{mg} \mathrm{kg}^{-1}\right)\end{array}$ & Analytical curve & $\mathrm{R}^{2}$ & $t_{\text {critical }}$ \\
\hline Twilight Yellow FCF & $50-150$ & $y=108.5 x+1939.70$ & 0.99941 & 9.28 \\
Erythrosine & $50-150$ & $y=3592.2 x+39858.82$ & 0.99871 & 71.36 \\
Orange G & $150-150$ & $y=2820 x+19016.62$ & 0.99967 & 9.28 \\
Tartrazine & $50-150$ & $y=6801.9 x+32082.39$ & 0.99985 & 9.28 \\
Allura Red & $50-150$ & $y=7489.7 x-27827.07$ & 0.99994 & 9.28 \\
\hline
\end{tabular}

Table 2. Results of veracity, repeatability and intermediate precision found for the method developed

\begin{tabular}{|c|c|c|c|c|c|c|}
\hline \multirow{2}{*}{ Analyte } & \multicolumn{3}{|c|}{ Repeatability } & \multicolumn{3}{|c|}{ Intermediate accuracy } \\
\hline & $50 \mathrm{mg} \mathrm{kg}^{-1}$ & $100 \mathrm{mg} \mathrm{kg}^{-1}$ & $150 \mathrm{mg} \mathrm{kg}^{-1}$ & $50 \mathrm{mg} \mathrm{kg}^{-1}$ & $100 \mathrm{mg} \mathrm{kg}^{-1}$ & $150 \mathrm{mg} \mathrm{kg}^{-1}$ \\
\hline Twilight Yellow FCF & $110(9.8)$ & $102(9.3)$ & $97(8.7)$ & 13.1 & 7.9 & 11.1 \\
\hline Erythrosine & $101(3.0)$ & $103(4.2)$ & $23(95.8)^{\mathrm{a}}$ & 3.3 & 4.7 & $78.2^{\mathrm{a}}$ \\
\hline Orange $\mathrm{G}$ & $101(9.1)$ & $106(7.4)$ & $105(10.5)$ & 19.0 & 7.0 & 10.6 \\
\hline Tartrazine & $109(8.2)$ & $102(6.0)$ & $101(10.1)$ & 11.5 & 5.4 & 8.4 \\
\hline Allura Red & $110(3.3)$ & $104(6.3)$ & $93(8.5)$ & 8.8 & 6.6 & 9.7 \\
\hline
\end{tabular}

${ }^{\mathrm{a}}$ Unsatisfactory results. Values of relative standard deviations (RSD) in parentheses. 
Table 3. Estimation of combined uncertainty (uc) and expanded measurement uncertainty (U) determined in the validation procedure of the quantitative method of analysis of food coloring in guava pulp

\begin{tabular}{|c|c|c|c|c|c|c|}
\hline \multirow{2}{*}{ Analyte } & \multicolumn{3}{|c|}{ Combined uncertainty } & \multicolumn{3}{|c|}{ Expanded uncertainty ${ }^{a}$} \\
\hline & $50 \mathrm{mg} \mathrm{kg}^{-1}$ & $100 \mathrm{mg} \mathrm{kg}^{-1}$ & $150 \mathrm{mg} \mathrm{kg}^{-1}$ & $50 \mathrm{mg} \mathrm{kg}^{-1}$ & $100 \mathrm{mg} \mathrm{kg}^{-1}$ & $150 \mathrm{mg} \mathrm{kg}^{-1}$ \\
\hline Twilight Yellow FCF & $6.92(13.8)$ & $12.9(12.9)$ & $18.8(12.5)$ & 13.5 & 25.2 & 36.9 \\
\hline Erythrosine & $6.48(13.0)$ & $10.8(10.8)$ & $15.1(10.0)$ & 12.7 & 21.1 & 29.5 \\
\hline Orange $\mathrm{G}$ & $5.06(10.1)$ & $10.2(10.2)$ & $15.3(10.2)$ & 9.91 & 19.9 & 29.3 \\
\hline Tartrazine & $1.78(3.56)$ & $3.18(3.18)$ & $4.59(3.06)$ & 3.5 & 6.2 & 9.0 \\
\hline Allura Red & $1.40(2.81)$ & $2.85(2.85)$ & $4.30(2.86)$ & 2.8 & 5.6 & 8.4 \\
\hline
\end{tabular}

${ }^{\mathrm{a}}$ Confidence level: $95 \%$; scope factor $(\mathrm{k}): 1.96$. Values of relative standard deviations (RSD) in parentheses.

MAPA..$^{24}$ The expanded uncertainty of the method is given by multiplying the combined uncertainty by the coverage factor adopted. The greatest contribution to the uncertainty of the method was given by the analytical curve, indicating that the curves should be analyzed and monitored as routine analyzes are performed.

\section{Analyses of authentic guava pulp samples}

The developed method was applied to the analysis of authentic samples. The results are shown in Table S2 (SI section). It can be seen that these samples did not show contamination with the dyes included in the method.

\section{Conclusions}

A simple and fast method was developed to determine five food dyes (Twilight Yellow FCF, Erythrosine, Orange G, Tartrazine and Allura Red) in guava pulp, consisting of a fibrous matrix, by reverse phase chromatography. Due to the anionic properties of the analytes, it is assumed that there is a strong interaction between them in aqueous solution. Thus, it was necessary to use formic acid in the mobile phase and also surfactant in solution in order to modify the characteristics of the C18 stationary phase, enabling chromatographic separation, that is, resolution between the peaks, and also reproducibility between consecutive injections. the analyzed analyte standards. The $\mathrm{pH}$ adjustment before the extraction of the analytes from the matrix was important to promote the desorption process of these compounds, while the $\mathrm{pH}$ adjustment after the extraction allowed a better chromatographic elution. The method was validated and met the criteria of veracity, repeatability and intermediate precision. Therefore, it can be concluded that the method can be applied in routine analyzes for quality control and food safety, following the main national and international standards of analytical quality. Finally, the method also allows the scope to be expanded, both to cover a greater number of analytes and to include other matrices.

\section{Supplementary Information}

Supplementary information (Tables S1-S2 and Figures S1-S8) is available free of charge at http://jbcs.sbq.org.br as PDF file.

\section{Acknowledgments}

The authors thanks to Coordenação de Aperfeiçoamento de Pessoal de Nível Superior-Brazil (CAPES), the Fundação de Amparo à Pesquisa do Estado de Minas Gerais (FAPEMIG) and the Conselho Nacional de Desenvolvimento Científico e Tecnológico (CNPq) for financial support; to the Ministério da Agricultura, Pecuária e Abastecimento (MAPA)-Brazil, for allowing the development of this work on its premises.

\section{Author Contributions}

Marina was responsible for the execution of all experimental activities and writing of the work; Fabiano helped in the optimization of the chromatographic analysis; Eugênia and Fernando helped in the optimization of chromatography, sample preparation and validation; Lucas helped to elucidate the elution model using surfactant, reviewing all calculus; Renata was the supervisor of the work, acting in the orientation of all the steps performed, writing and correction of the text.

\section{References}

1. Martins, F. C. O. L.; Sentanin, M. A.; de Souza, D.; Food Chem. 2019, 272, 732.

2. Wu, H.; Guo, J. B.; Du, L. M.; Tian, H.; Hao, C. X.; Wang, Z. F.; Wang, J. Y.; Food Chem. 2013, 141, 182.

3. Bonan, S.; Fedrizzi, G.; Menotta, S.; Elisabetta, C.; Dyes Pigm. 2013, 99, 36.

4. Martin, F.; Oberson, J. M.; Meschiari, M.; Munari, C.; Food Chem. 2016, 197, 1249. 
5. de Andrade, F. I.; Guedes, M. I. F.; Vieira, Í. G. P.; Mendes, F. N. P.; Rodrigues, P. A. S.; Maia, C. S. C.; Ávila, M. M. M.; Ribeiro, L. M.; Food Chem. 2014, 157, 193.

6. Hu, Z.; Qi, P.; Wang, N.; Zhou, Q. Q.; Lin, Z. H.; Chen, Y. Z.; Mao, X. W.; Jiang, J. J.; Li, C.; Food Chem. 2020, 309, 125745.

7. Qi, P.; Lin, Z. H.; Chen, G. Y.; Xiao, J.; Liang, Z. A.; Luo, L. N.; Zhou, J.; Zhang, X. W.; Food Chem. 2015, 181, 101.

8. Sebaei, A. S.; Youssif, M. I.; Abdel-Maksoud Ghazi, A.; J. Food Compos. Anal. 2019, 84, 103304.

9. Chen, X. H.; Zhao, Y. G.; Shen, H. Y.; Zhou, L. X.; Pan, S. D.; Jin, M. C.; J. Chromatogr. A 2014, 1346, 123.

10. Vidotti, E. C.; Costa, W. F.; Oliveira, C. C.; Talanta 2006, 68, 516.

11. Al-Degs, Y. S.; Food Chem. 2009, 117, 485.

12. Zou, T.; He, P.; Yasen, A.; Li, Z.; Food Chem. 2013, 138, 1742.

13. Bento, W. A. S.; Lima, B. P.; Paim, A. P. S.; Food Chem. 2015, 183, 154.

14. European Commission; Commission Regulation (EU) No. 1129/2011 of 11 November 2011, Amending Annex II to Regulation (EC) No 1333/2008 of the European Parliament and of the Council by Establishing a Union List of Food Additives; Official Journal of the European Union, 2011, available at https://eur-lex.europa.eu/legal-content/EN/TXT/PDF/?uri=C ELEX:32011R1129\&from=PT, accessed in July 2021.

15. Agência Nacional de Vigilância Sanitária (ANVISA); Resolução da Diretoria Colegiada (RDC) No. 8 de 6 de março de 2013, Dispõe sobre a Aprovação de Uso de Aditivos Alimentares para Produtos de Frutas e de Vegetais e Geleia de Mocotó; Diário Oficial da União (DOU), Brasília, de 8 de março de 2013, available at https://www.gov.br/agricultura/pt-br/assuntos/ inspecao/produtos-vegetal/legislacao-1/biblioteca-de-normasvinhos-e-bebidas/resolucao-rdc-no-8-de-6-de-marco-de-2013. pdf/view, accessed in July 2021.

16. Tsai, C. F.; Kuo, C. H.; Shih, D. Y. C.; J. Food Drug Anal. 2015 , 23, 453.

17. Karanikolopoulos, G.; Gerakis, A.; Papadopoulou, K.; Mastrantoni, I.; Food Chem. 2015, 177, 197.

18. da Silva, B. F.; Souza, J. C.; Zanoni, M. V. B. In Corantes: Caracterização Química, Toxicológica, Métodos de Detecção e Tratamento; Cultura Acadêmica: São Paulo, 2016, p. 179-197.

19. da Silva, C. G. A.; Bottoli, C. B. G.; Collins, C. H.; Quim. Nova 2016, 39, 210 .
20. Yamjala, K.; Nainar, M. S.; Ramisetti, N. R.; Food Chem. 2016, 192, 813.

21. Prado, M. A.; Godoy, H. T.; Quim. Nova 2004, 27, 22.

22. Iammarino, M.; Mentana, A.; Centonze, D.; Palermo, C.; Mangiacotti, M.; Chiaravalle, A. E.; MethodsX 2019, 6, 856.

23. Jiménez-Escrig, A.; Rincón, M.; Pulido, R.; Saura-Calixto, F.; J. Agric. Food Chem. 2001, 49, 5489.

24. Ministério da Agricultura (MAPA); Manual de Garantia da Qualidade Analítica para Resíduos e Contaminantes em Alimentos, available at https://www.gov.br/agricultura/ptbr/assuntos/laboratorios/arquivos-publicacoes-laboratorio/ manual-de-garantia-analitica-ilovepdf-compressed-ilovepdfcompressed.pdf/, accessed in July 2021.

25. European Commission Directorate-General for Health and Food Safety; SANTE/11813/2017, Guidance Document on Analytical Quality Control and Method Validation Procedures for Pesticide Residues and Analysis in Food and Feed, available at https://www.eurl-pesticides.eu/docs/public/tmplt_article. asp?CntID=727, accessed in July 2021.

26. Joint Committee for Guides in Metrology (JCGM); GUM-6:2020 Guide to the Expression of Uncertainty in Measurement Part 6: Developing and Using Measurement Models; JCGM, 2020, available at: https://www.bipm.org/documents/20126/2071204/ JCGM_GUM_6_2020.pdf/d4e77d99-3870-0908-ff37c1b6a230a337, accessed in July 2021

27. Molognoni, L.; Daguer, H.; de Sá Ploêncio, L. A.; de Dea Lindner, J.; Talanta 2018, 178, 1053.

28. Jalili, V.; Barkhordari, A.; Ghiasvand, A.; Microchem. J. 2020 , 153, 104386.

29. Vieira, H. P.; Neves, A. A.; de Queiroz, M. E. L. R.; Quim. Nova 2007, 30, 535.

30. Mosquetta, R.; Ribeiro, G. C.; Munoz, R. A. A.; Coelho, N. M. M.; Coelho, L. M.; Quim. Nova 2011, 34, 923.

31. Salleh, M. A. M.; Mahmoud, D. K.; Karim, W. A. W. A.; Idris, A.; Desalination 2011, 280, 1.

32. Aramwit, P. In Wound Healing Biomaterials, vol. 2; Ågren, M. S., ed.; Elsevier Science: San Diego, CA, USA, 2016, p. 3-38.

33. Tiwari, B. K.; TrAC, Trends Anal. Chem. 2015, 71, 100.

34. Sha, O.; Zhu, X.; Feng, Y.; Ma, W.; Food Chem. 2015, 174, 380.

Submitted: January 3, 2021

Published online: July 23, 2021 